\title{
Researching Aptitude in a Process-based Approach to Foreign Language Writing Instruction
}

\author{
Abbas zare-ee \\ English Department, University of Kashan, Kashan, 87317-51167, Iran \\ E-mail: Zare-ee72@kashanu.ac.ir \\ Fatemeh Mahdavi \\ English Department, Faculty of Arts and humanities, University of Kashan
}

Doi:10.7575/aiac.alls.v.5n.5p.22

URL: http://dx.doi.org/10.7575/aiac.alls.v.5n.5p.22
Received: 14/06/2014

Accepted: 12/08/2014

\begin{abstract}
In the study reported here, we explored writing processes employed by 70 undergraduate learners of English as a Foreign Language (EFL) through questionnaires and think-aloud protocols. Then we looked for possible differences in the writing processes employed by high- and low-aptitude learners. We observed that learners with higher aptitude scores devoted more attention to clausal complexity than those with lower levels of aptitude. Moreover, they resorted less frequently to their mother tongue while writing texts in English. High-aptitude EFL learners also used more global planning strategies than their low-aptitude peers and edited while writing much more frequently. Our review showed that even though aptitude has been extensively researched in second language acquisition and shown to correlate with the level of success in different skills, it has rarely been considered in relation to writing processes. We suggest that, as classroom teachers, EFL writing instructors accumulate and incorporate knowledge of their students' aptitude in deploying their teaching strategies.
\end{abstract}

Keywords: second language writing, writing strategies, language learning aptitude, individual differences, EFL

\section{Introduction and background}

The present study investigated the writing processes of Iranian EFL learners with two different levels of second language (L2) aptitude (high- and low- aptitude). Although the role of aptitude as a possible individual difference in second language (L2) speech has been extensively studied, very few studies have examined its impact on the processes of second language writing and language learners' different uses of writing processes. The present study, therefore, looked at a relatively unexplored area in that it tried to focus on aptitude-related process differences in EFL writing observed while the act of writing was in progress. Why EFL learners show great variations in their language learning success is the question that has stimulated a lot of research conducted in the field of second language acquisition (SLA) (Kormos \& Trebits, 2012). Studies focusing on this area have introduced individual differences (IDs) as important predictors of achievement in a second language (Dörnyei, 2005). It is widely recognized that IDs have to be taken into consideration both in theoretical accounts of SLA and in practical pedagogical decision-making (Dörnyei, 2005). Researchers often acknowledge the necessity of making further advances into investigating how certain IDs affect and underlie important language learning processes (Dörnyei, 2005; Kormos \& Sáfár, 2008; Robinson, 2007a). Therefore, the role of individual differences in the ultimate achievement of language competence has been excessively studied and there is a plethora of research on how cognitive factors influence L2 speaking (Dornyei \& Kormos, 2000; Kormos \& Trebits, 2012) and reading skills (Grabe, 2009). According to Dörnyei (2005), learner variables are usually categorized into cognitive, affective and personality-related IDs.

One of the most important cognitive variables influencing the success of language learning is foreign language aptitude, which is assumed to be a combination of cognitive factors that might potentially affect the success of language learning (Carroll, 1981). The study of aptitude, and the impact of aptitude research, was restricted considerably by the 1970s. There were several reasons for this paucity as mentioned by Skehan (2002). Foreign language aptitude was considered as anti-egalitarian. Testing someone's aptitude and assigning them a score implied that an ultimate language learning capacity had been measured that could shape the ultimate level of achievement irrespective of learner efforts. In addition, aptitude was associated with outdated methodologies (e.g. audio-lingual methodologies). A third reaction to aptitude work was the possible benefits of indifference to differences between learners, of the belief that all learners are the same, and the excellence of the materials is the over-riding issue.

Despite the earlier criticisms (in the 1970s \& 1980s) of being outmoded and ineffective, the concept of foreign language aptitude is still relevant to foreign language learning. Furthermore, the effect of foreign language aptitude is not confined to traditional instructed settings, but has also the capacity to change under different learning circumstances or under different learning contexts in today's communicative classrooms. In recent perception of foreign language aptitude, it is argued that different cognitive abilities might be beneficial in different phases and processes of language 
learning (Skehan, 2002). Different cognitive ability profiles might necessitate different types of learning tasks (Robinson, 2005). Robinson stated that second language (L2) learning aptitude was characterized as strengths individual learners had in the cognitive abilities used in information processing.

The importance of individual differences has been highlighted in many studies in L1 writing research (Pajares, 2003). However, little is known about how learner differences affect L2 writing processes. In the proliferating filed of L2 writing research, this lack of attention to individual factors in relation to L2 writing processes is surprising, as writing is a complex process requiring the skillful regulation of diverse elements of cognitive and linguistic processes (Hayes, 1996; Kellogg, 1996). Writing is not only a complex task but also a time-consuming activity that requires concentration and determination. Unlike speaking, it is acquired through teaching. It requires instruction, practice, and experience. It is not included in the process of regular maturity. And the learner's profile can become extremely important under these circumstances. Scholars (e.g. Kroll, 1990) have confirmed that writing is challenging and requires the writer to be aware of and combine various components of language successfully. Therefore, individuals with different cognitive abilities and different aptitudes can be expected to execute and organize writing processes with varying degrees of efficiency.

In looking at cognitive factors in SLA, the role of foreign language aptitude has been extensively researched. For a long time, researchers showed interested in uncovering the relationship between foreign language aptitude and language learning outcomes (Grigorenko, Sternberg \& Ehrman, 2000). For example, Grigorenko, et.al (2000) collected data on the links between previous exposure to Foreign Language (FL) learning and FL aptitude. These researchers found a connection between the number of languages a person could speak/ read/ write and higher levels of language aptitude. In this work, the researchers were interested in how an understanding of the role of individual differences in writing processes could offer insights to the field of second language writing. In other words, the study looked at how a cognitive factor could influence how and to what extent EFL learners exploited learning opportunities offered by EFL writing tasks. So far, valuable works on L2 writing processes (e.g. Raimes, 1985) have explored the composing processes and examined the influences of L2 proficiency on their deployment and use.

\section{The purpose of the study}

While research on identifying L2 writing processes has been valuable for advancing the understanding of the nature of these processes, L2 proficiency alone cannot be considered the only or the most important factor influencing the use of writing processes. As Kormos (2012) stated 'it can be speculated that aptitude as a cognitive ability specific to language might influence L2 writing processes that involve linguistic processing and draw on linguistic resources' (p. 396). Unfortunately, in the L2 writing research there are very few studies that have investigated the role that aptitude may paly in shaping L2 writing processes. The question for which this study seeks answers is this: "how does aptitude as defined and measured here influence the writing processes of the Iranian university level EFL learners"? More specifically, the present study aimed at testing the speculation by Kormos (2012) that aptitude as a cognitive ability specific to language might influence L2 writing processes that involve linguistic processing and draw on linguistic recourses. Kormos thinks that the stages of writing where high aptitude learners might be advantaged are most likely to be the translation and reviewing phases, and not the stages where content is generated and organizational decisions are made. He writes,

“...as for the translation of ideas into linguistic units, L2 learners with high levels of grammatical sensitivity and good deductive abilities can be assumed to handle the grammatical encoding of the conceptual plan more efficiently than writers with lower levels of aptitude. Consequently, high aptitude learners might devote more attention to the syntactic complexity of their text and their writing might display higher levels of linguistic accuracy" (p. 396).

\section{Research Methodology}

In this study, we took advantage of both quantitative and qualitative approaches to investigate the writing processes of the two groups of EFL learners, the high- and the low-aptitude learners. First, a Quantitative Approach was utilized to distinguish sub-groups of learners based on the independent variable of Aptitude. Moreover, writing processes tested through questionnaires needed to be described in a more quantitative approach. Qualitative analyses were also employed to analyze the probable relationships between aptitude and writing processes. To investigate differences and similarities among learners with high and low degrees of language learning aptitude in terms of actually-used processes, qualitative data and analyses were deemed appropriate. The main variables which we investigated were a) writing processes (as dependent variables) and b) aptitude (as the independent variable of the study).

\subsection{Participants}

In order to answer the research question, the study sought the participation of a total of 70 undergraduate Iranian EFL learners studying at the English Department of a public university. They had already passed their EFL writing courses. The respondents were selected on the basis of convenient sampling. Data came from any participant who was available and consented to provide the data for the research. Almost all the learners in the department had to be addressed as the aptitude test was not familiar and not many learners liked to test/reveal their aptitude. The test was also thought tobe difficult and time-consuming to take.

\subsection{Materials}

The instrument used to assess EFL learners' aptitude in learning a second language was THE COLLEGES OF OXFORD UNIVERSITY CLASSICS LANGUAGE APTITUDE TEST (Specimen of Written Test at Interview Issued 2010). The purpose of the test was to measure the extent to which EFL learners were ready to go through learning a 
second language. Based on the result of a pilot study and due to limitations in applying a full-fledged aptitude test (e.g. MLAT), we decided to make the test shorter. The item leads in this test were translated into Persian in order to make the instructions easier for learners to understand. Due to the limited time in the each data collection session (90 minutes of the class time) and the slowness of the respondents, some parts of the test had to be left out. Moreover, the researchers decided to modify the order of the sections in the aptitude test to fit the context. In order to observe the complex processes/strategies that these EFL learners used while composing in English, think-aloud protocol was used as a promising means of collecting data. "The name itself suggests that the think-aloud technique is one in which subjects perform a task or solve a problem and verbalize their thought processes as they are doing so (Nunan, 1992). In this technique, the researcher collected the think-aloud protocols on tape and then analyzed the information.

\subsection{Procedure}

In investigating the differences and similarities among EFL learners with different levels of L2 aptitude in terms of EFL writing strategies and behavior, as the main theme of this study, the following procedure was adopted. Having expressed the purpose of the study to the learners, the researchers administered the aptitude test to all the participants. In this test, the respondents were instructed to follow the directions provided for them in their mother tongue. When the data on aptitude were collected (within one month), six of the learners with the highest and lowest aptitude test scores were asked to think aloud as they wrote in English. In this think-aloud technique, attempts were made to record everything the EFL writers said as they wrote. Participants were given instructions on what to do and provided with a tape-recorder to turn on as soon as they started to plan writing. During the think-aloud, the researcher reminded the subjects about what to do by attracting their attention to the protocol instructions and the assigned topic. The researcher translated and explained the English topic and gave each person a chance to ask for clarifications before starting writing if there were any unclear issues. Having finished the think aloud phase, the researchers focused on retrospective accounts in whichever language the subject felt comfortable to respond in. This was held in a quiet room with a tape-recorder on a table in front of the subject to record verbalized retrospections. Recording started when the learners was ready to begin writing. The researcher sat at the back observing the subject, always encouraging him/her to speak out while writing.

\subsection{Coding the data}

Utilizing a think-aloud technique is not an easy task. It demands certain skills and imposes limitations on the researcher and the participants. The researcher must be patient with the subjects while producing their writing tasks by reminding them to keep talking-aloud and by wittingly answering their questions. Once the think-alouds were recorded, the tapes were transcribed and analyzed using Perl's (1984) coding scheme. In addition, the researcher made modifications where necessary to adequately cover a variety of the composing aspects and processes. During the observation of the subjects' writing, behaviors such as actual writing, pausing, reading, rehearsing, translating, and making changes in the text were coded to confirm the frequency and context of each behavior in the writing process. Listening to the learners as they verbalized their thought processes during text production, the researchers recorded what they did as they planned, drafted, and reviewed. That is, they used the three main process stages while producing their written work.

\section{Analysis and Results}

The learners' aptitude test results were summarized and analyzed using the SPSS software (version 18). Think-aloud data was also a fundamental part of the research on learners with different levels of aptitude. Tape-recorded data for four female and two male EFL writers, included clear verbalizations on problems faced during all stages of writing, namely, planning, drafting and revising. The first part of data analysis was the determination of the aptitude profile of the sample. Table 1 shows the basic statistics on aptitude. Considering the total mean and standard deviation and concentrating on the learners falling in \pm 3 SDs of the mean, the researchers could compare high- and low-aptitude learners (10 \& 11 learners respectively). T-test results, summarized in Table 2, showed that these learners were significantly different in the mean aptitude score and the researchers could therefore consider comparing writing processes employed by learners across aptitude levels. The results of the 2-tailed test showed that the differences between the groups of low- and high-aptitude learners were significant $(\mathrm{t}=17.65, \mathrm{df}=19)$ at the 0.01 level.

Table 1. Mean and SDs for aptitude test scores

\begin{tabular}{lllll}
\hline & $\mathrm{N}$ & Mean & $\mathrm{SD}$ & $\begin{array}{l}\text { Varianc } \\
\mathrm{e}\end{array}$ \\
\hline All learners & & & 10.22748 & 104.601 \\
Low aptitude & 69 & 56.6 & 4.31830 & 1.30202 \\
High aptitude & 11 & 41.5 & 3.85726 & 1.21977 \\
\hline
\end{tabular}

Table 2. T-test comparing Low- aptitude and High- aptitude learners

Levene's Test for Equality of Variances t-test for Equality of Means

\begin{tabular}{llllll} 
& $\mathrm{F}$ & $\mathrm{Sig}$. & $\mathrm{t}$ & $\mathrm{df}$ & Sig. \\
\hline $\begin{array}{l}\text { Equal variances assumed } \\
\begin{array}{l}\text { Equal variances not } \\
\text { assumed }\end{array}\end{array}$ & .197 & .663 & -17.652 & 19 & .000 \\
\hline
\end{tabular}


Formulation, execution, and monitoring processes in producing written products were compared by looking at the thinkaloud reports provided by 3 high and three low aptitude learners. The following characteristics were noted based on the data presented below: a) all subjects mentally planned and generated ideas in L1 before writing their essays in English; b) the subjects in the Low-aptitude (LA) group did not organize their ideas in any way; c) the subjects in the Highaptitude (HA) group did develop (mentally) their ideas to form a unified text before actual writing; d) some of the subjects' plan changed as they finished their process of writing; e) all learners used L1, some extensively, while producing EFL essays; f) all the learners paused for different reasons while writing in EFL; g) just one learner started rewriting without being instructed to do so; $h$ ) the learners in the LA group emphasized the importance of developing the content rather than the grammar of the work; i) only two of the learners thought aloud naturally (without elicitation) in the process of writing; j) all learners tried hard to find appropriate vocabulary, hesitated over spelling, and confused the mechanics of English writing conventions; k) all went back and forth between L2 and L1; and 1) all learners made internal revisions but not all considered final revisions.

Table 3 shows the frequency of writing strategies used by three low- and three high-aptitude learners in each subprocess of planning, drafting, and revising. In this section, the aim is to summarize the writing strategies employed by the learners while composing in English. The first three learners are the high aptitude and the second three are the low aptitude ones. The main process subcategories are divided into further subcategories. For instance, planning itself contains overt planning, covert planning, local planning and global planning for which the researchers have accumulated detailed classifications and frequency counts. A close examination of row and column subtotals and totals of EFL writing processed in Table 3 indicates that the configuration of sub-processes is different for LA and HA learners. Suprizingly, total strategy frequency favors the LA group.

Table 3: Composing strategies actually used by three high- and three low-aptitude EFL learners

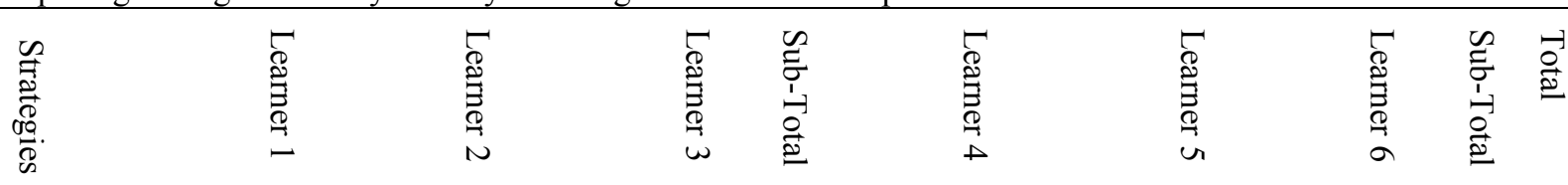

\begin{tabular}{|c|c|c|c|c|c|c|c|c|c|}
\hline Planning & $7(10 \%)$ & $\begin{array}{l}34(10.27 \\
\%)\end{array}$ & $5(4.03 \%)$ & 46 & $\begin{array}{l}10(4.87 \\
\%)\end{array}$ & $11(6.62 \%)$ & $\begin{array}{l}19(11.37 \\
\%)\end{array}$ & 40 & $\begin{array}{l}8 \\
6\end{array}$ \\
\hline Rehearsing & $11(15.71 \%)$ & $\begin{array}{l}98(29.60 \\
\%)\end{array}$ & $14(11.29 \%)$ & 123 & $\begin{array}{l}72(35.12 \\
\%)\end{array}$ & $\begin{array}{l}28(16.86 \% \\
)\end{array}$ & $\begin{array}{l}34(20.35 \\
\%)\end{array}$ & 134 & $\begin{array}{l}2 \\
5 \\
7\end{array}$ \\
\hline Rescanning & $5(7.14 \%)$ & $\begin{array}{l}42(12.68 \\
\%)\end{array}$ & $45(36.29 \%)$ & 92 & $\begin{array}{l}40(19.51 \\
\%)\end{array}$ & $\begin{array}{l}36(21.68 \% \\
)\end{array}$ & $\begin{array}{l}23(13.77 \\
\%)\end{array}$ & 99 & $\begin{array}{l}1 \\
9 \\
1\end{array}$ \\
\hline Repeating & $3(4.28 \%)$ & $4(1.20 \%)$ & $3(2.41 \%)$ & 10 & $2(0.97 \%$ & -- & $5(2.99 \%)$ & 7 & $\begin{array}{l}1 \\
7\end{array}$ \\
\hline $\begin{array}{l}\text { Rereading the } \\
\text { assigned topic }\end{array}$ & $1(1.42)$ & $10(3.02 \%$ & $3(2.41 \%)$ & 14 & $\begin{array}{l}11(5.36 \\
\%)\end{array}$ & $9(5.42 \%)$ & $5(2.99 \%)$ & 25 & $\begin{array}{l}3 \\
8\end{array}$ \\
\hline $\begin{array}{l}\text { Language } \\
\text { Switch }\end{array}$ & $14(20 \%)$ & $\begin{array}{l}93(28.09 \\
\%)\end{array}$ & $26(20.96 \%)$ & 133 & $\begin{array}{l}40(19.51 \\
\%)\end{array}$ & $\begin{array}{l}34(20.48 \% \\
)\end{array}$ & $\begin{array}{l}45(26.94 \\
\%)\end{array}$ & 119 & $\begin{array}{l}2 \\
5 \\
2\end{array}$ \\
\hline $\begin{array}{l}\text { External } \\
\text { Resources }\end{array}$ & -- & -- & -- & & -- & -- & -- & & \\
\hline $\begin{array}{l}\text { Self- } \\
\text { Questioning }\end{array}$ & $4(5.71 \%)$ & $16(4.83 \%$ & $3(2.41 \%)$ & 23 & $\begin{array}{l}15(7.31 \\
\%)\end{array}$ & $9(5.42 \%)$ & $7(4.19 \%)$ & 31 & $\begin{array}{l}5 \\
4\end{array}$ \\
\hline $\begin{array}{l}\text { Self- } \\
\text { Reinforcemen } \\
t\end{array}$ & $1(1.42 \%)$ & -- & $1(0.80 \%)$ & 2 & -- & $1(0.60 \%)$ & -- & 1 & 3 \\
\hline $\begin{array}{l}\text { Invoking G. } \\
\text { Rules }\end{array}$ & $2(2.85 \%)$ & $4(1.20 \%)$ & $3(2.41 \%)$ & 9 & $1(0.48 \%$ & $2(1.20 \%)$ & $1(0.59 \%)$ & 4 & $\begin{array}{l}1 \\
3\end{array}$ \\
\hline Commenting & -- & $5(1.51 \%)$ & -- & 5 & $\begin{array}{l}2(0.97 \% \\
)\end{array}$ & $6(3.61 \%)$ & $5(2.99 \%)$ & 13 & $\begin{array}{l}1 \\
8\end{array}$ \\
\hline Postponing & $1(1.42 \%)$ & $1(0.30 \%)$ & $1(0.80 \%)$ & 3 & -- & -- & -- & & 3 \\
\hline $\begin{array}{l}\text { Defining } \\
\text { Terms }\end{array}$ & -- & $1(0.30 \%)$ & -- & 1 & -- & -- & -- & & 1 \\
\hline Guessing & $1(1.42 \%)$ & $6(1.81 \%)$ & $1(0.80 \%)$ & 8 & $\begin{array}{l}6(2.92 \% \\
)\end{array}$ & $3(1.80 \%)$ & $5(2.99 \%)$ & 14 & $\begin{array}{l}2 \\
2\end{array}$ \\
\hline Abandoning & $1(1.42 \%)$ & $5(1.51 \%)$ & $1(0.80 \%)$ & 7 & $4(1.95 \%$ & $2(1.20 \%)$ & $3(1.79 \%)$ & 9 & $\begin{array}{l}1 \\
6\end{array}$ \\
\hline Revising & $7(10 \%)$ & $8(2.41 \%)$ & $13(10.48 \%)$ & 28 & $1(0.48 \%$ & $\begin{array}{l}23(13.85 \% \\
)\end{array}$ & $\begin{array}{l}10(5.98 \% \\
0\end{array}$ & 34 & $\begin{array}{l}6 \\
2\end{array}$ \\
\hline Editing & $12(17.14 \%)$ & $3(0.90 \%)$ & $3(2.41 \%)$ & 18 & -- & $1(0.60 \%)$ & $3(1.79 \%)$ & 4 & $\begin{array}{l}2 \\
2\end{array}$ \\
\hline Reviewing & $1(1.42 \%)$ & $1(0.30 \%)$ & $2(1.61 \%)$ & 4 & )$^{1(0.48 \%}$ & $1(0.60 \%)$ & $2(1.19 \%)$ & 4 & 8 \\
\hline Total & $71(100 \%)$ & $\begin{array}{l}331(100 \\
\%)\end{array}$ & $124(100 \%)$ & 526 & $\begin{array}{l}205(100 \\
\%)\end{array}$ & $166(100 \%)$ & $\begin{array}{l}167(100 \\
\%)\end{array}$ & 538 & \\
\hline
\end{tabular}


To make a better sense of the data in Table 3, instances of transcribed data based on which the frequency of used processes were counted and tabulated are reported below. As for planning, all subjects devoted some time to planning before starting to write (HA learners 46 times and LA learners 40 times. In global planning, learner 1 said, "well,..., first I think I have to define this and explain how much of it can be innate or derived from experience...then, I will explain that I think its more innate...." (TS 1) In local planning, learner 5 said, "I have a hard time starting this...Should I have brought this section later in my writing"? (TS 2). While rehearsing and mentally searching for and generating the right ideas, learners 2 and 4 rehearsed various words, phrases, full sentences, and ideas more than others: "Well, each theory can befalsified...."(TS 3); ... "I can write about the month I was born". (TS 4)

For the rescanning process, all the 6 learners did a great deal of rereading part of a sentence, all of a sentence, or all of the sentences they had written. Learner 5 thought aloud: "the third case....the third case ....could be...the third case could be ........the word.......ASGOZAR....effective in ....creating... no... in developing... in developing personality...personality development... the third case could be effective in developing personality is.......for example: having relationship with the people who are from... for example: having relationship with the people who are from..." Unlike learners 2 and 3 who showed the least effort to read what they had written, others often employed this strategy when they got stuck. The reading strategy was generally adopted when the subjects wanted to choose a suitable word, or begin a new sentence, when they were stuck in finding new ideas. "I should now read one more time to see what I have so far written". (TS 5).

Learners also monitored what they wrote. “....just a few second... seconds after birth he or she or ones ...No... he or she react...reacts...reacts the surrounding world. Or "...for example, some people are very kind and in every condition they are kind...... [ what about patient for kind here?]....for example, some people are very patient and in every condition they are patient..... Although, the subjects asked for help whenever they faced any problems related to special vocabulary or grammatical point of view, they were not allowed to get any kind of help from outside, i.e. dictionary, asking the researcher for the needed word or structure. One common strategy in almost every writing sub-process was selfquestioning. The learners did not ask themselves whether their essays were well-organized or whether the content was coherent (This was seen only in high aptitude learners). However, their self-questioning reflected hesitations or asking their inner selves or helpless seeking for help from the present researcher: ... should I....shouldn't I?.. Till now...yes or no? ... Do I know how to say this... well, can experience be relevant here?" (TS 6). Learners also tried to define terms: “... all human beings share ....the motif of... [I want to say BARTARITALABI/TA'ALITALABI...well I will say it in a phrase....the motif of trying to be a better person in each or every aspect? in each aspect of... in each aspect, ... tendency toward goodness, etc". (TS 7)

\section{Discussion and Conclusion}

The analysis of the writing processes and strategies of these subjects showed differences and similarities between the two groups of subjects. Analyzing their think- aloud protocols, we noticed that the low aptitude group relied mostly on translation from Farsi to English, i.e., they thought in Persian and then translated their thoughts into English before they wrote them down. The use of L1 while composing in L2 took place at different levels such as the word, phrase and sentence level. The subjects applied language switch and translation because these strategies seemed to facilitate the writing act for them and they were considered integral parts of their composing processes. If they had not resorted to these techniques, the subjects would have failed and would have stopped writing much earlier, producing much shorter paragraphs.

Another important finding was that all the subjects expressed that they knew where their destinations were, but, only, the subjects in the high aptitude group tended to benefit from explicit planning before they engaged in L2 writing. Low aptitude learners seemed to be in a rush to get through the tasks in order to "generate texts". They used mental planning in Persian. However, HA learners planned their English texts covertly but globally.

All the learners in both groups got into trouble with lexis, grammar, and mechanics which forced them to verbalize their difficulties in L1. It was also observed that mostly low aptitude learners switched from L2 to L1 when they had difficulty generating ideas in L2, but none of them wrote the first draft in Farsi or translated the entire text in order to keep their cognitive loads as low as possible. Unlike high aptitude learners, the low aptitude ones adopted a more local planning strategy through the whole writing processes. The observed processes were totally recursive. In other words, learners used the three-process pattern of writing, repeating, and rehearsing at various intervals. For example, while writing, they interrupted themselves by commenting, questioning, evaluating, reading, and revising. They shuttled back and forth among these processes. HA learners revised and edited their texts more and paid attention to lexical items, sentence construction and idea generation at the same time. LA leaners were concerned more with idea generation alone. They paid little attention or no attention to organization in L2. This seems to imply that text-generating activity might be the most difficult among all composing activities.

The findings and observation in this study confirm findings of previous process research (e. g. Raimes, 1995) that writing is non-linear, forcing learners to move back and forth in the processes of planning, composing, and reviewing. They question is that HA and LA learners may not go to the same direction when they go back and forth. The performance of the High Aptitude (HA) EFL learners in this study confirmed the hypothesis by Kormos that the stages of writing where high aptitude EFL learners might benefit are most likely to be the translation and reviewing stages, and not the stages where content is generated and organizational decisions are made. 


\section{References}

Cambridge, E. S. O. L. (2006). Cambridge IELTS 5 Self Study Pack. Cambridge University Press.

Carroll, J. B. (1981). Twenty-five years of research on foreign language aptitude. In K. C. Diller (Ed.), Individual differences and universals in language learning aptitude (pp. 119-154). Rowley, MA: Newbury House.

Dörnyei, Z. (2005). The psychology of the language learner. Mahwah NJ: Lawrence Erlbaum.

Dornyei, Z., \& Kormos, J. (2000). The role of individual and social variables in oral task performance. Language Teaching Research, 4, 275-300.

Grabe, W. (2009). Reading in a second language. Moving from theory to practice. Cambridge: Cambridge University Press.

Grabe, W. \& Kaplan, R. B. (1996). Theory and practice of writing. London: Longman.

Grigorenko, E. L., Sternberg, R. J., and Ehrman, M. E. (2000). "A theory-based approach to the measurement of foreign language learning ability: the CANAL-F theory and test". Modern Language Journal 84/3. 390-405.

Hayes, J. R. (1996). A new framework for understanding cognition and affect in writing. In C. M. Levy \& L. S. Ransdell (Eds.),The science of writing: Theories, methods, individual differences and applications (pp. 1-27). Hillsdale, NJ: Erlbaum.

Kellogg, R.T. (1996). A model of working memory in writing. In C. M. Levy \& S. Ransdell (Eds.), The science of writing: Theories, methods, individual differences and applications (pp. 57-71). Mahwah, NJ: Lawrence Erlbaum.

Kormos, J. (2012). The role of individual differences in L2 writing. Journal of Second Language Writing, 21(4), 390-403.

Kormos, J., \& Safar, A. (2008).Phonological short term-memory, working memory and foreign language performance in intensive language learning. Bilingualism: Language and Cognition, 11, 261-271.

Kormos, J., \& Trebits, A. (2012). The role of task complexity, modality and aptitude in narrative task performance. Language Learning, 62(2), 439-472.

Kroll, B. (1990). Second language writing. New York: Cambridge University Press.

Nunan, D. (1992). Research methods in language learning. C.U. P.

Pajares, F. (2003). Self-efficacy beliefs motivation and achievement in writing: A review of the literature. Reading and Writing Quarterly, 19, 139-158.

Raimes, A. (1985). What unskilled writers do as they write. A classroom study of composing. TESOL Quarterly 19 (2): 229-258.

Robinson, P. (2005). Aptitude and second language acquisition. Annual Review of Applied Linguistics, 25, 45-73.

Robinson, P. (2007a). Aptitudes, abilities, contexts and practice. In R. DeKeyser (Ed.), Practice in a second language: Perspectives from cognitive psychology and applied linguistics (pp. 256-286). Cambridge: Cambridge University Press.

Skehan, P. (2002). Theorising and updating aptitude. In P. Robinson (Ed.), Cognition and second language instruction (pp. 69-93). Cambridge: Cambridge University Press.

The colleges of oxford university classics language aptitude test (Specimen of Written Test at Interview Issued 2010. Oxford: Oxford University Press.

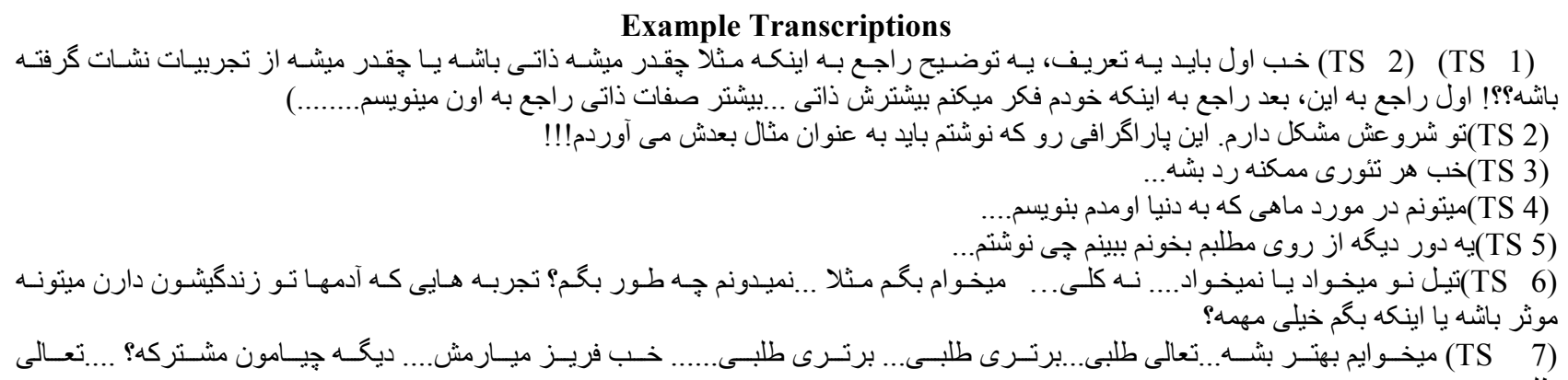

